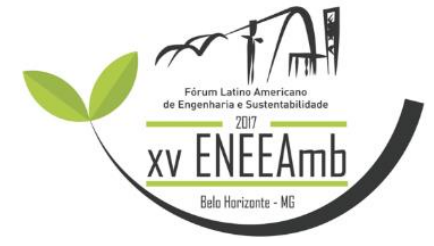

Luana Barbosa ${ }^{1}$

Julio Cezar Rubin de Rubin ${ }^{2}$

\title{
Diagnóstico ambiental da bacia do Córrego Baixa Funda em Araguaína - TO: resultados parciais
}

\section{RESUMO}

Resumo: Os impactos ambientais identificados na bacia hidrográfica do córrego Baixa Funda indicam uma ocupação urbana intensa e desordenada, resultando, principalmente, no surgimento de processos erosivos, assoreamento, lançamento de efluentes sem tratamento e retirada da mata ciliar. Para tanto o diagnóstico ambiental da área é um instrumento importante para a proposição de medidas mitigatórias e subsidiar novas pesquisa na área e em outras bacias hidrográficas do munícipio de Araguaína - TO. A metodologia utilizada constitui em levantamento de campo através de geoprocessamento e coleta de amostras de água. A intervenção antrópica na gestão dos recursos hídricos está diretamente ligada à disposição irregular de resíduos sólidos e má gestão pública.

Palavras-chave: Diagnóstico ambiental, urbanização, impacto.

\section{INTRODUÇÃO}

$\mathrm{O}$ crescimento urbano desordenado tem causado uma série de impactos ambientais e preocupações por parte da população, gestores e pesquisadores, tornando cada vez mais necessária a identificação dos fatores que influenciam na qualidade do meio ambiente. Segundo Neves e Tucci (2008a) a gestão inadequada da infraestrutura de saneamento é uma das causas dos impactos ambientais e da perda de qualidade de vida, sobretudo nos

\footnotetext{
${ }^{1}$ Enga ambiental, especialista em Segurança do Trabalho e Mestranda em Ciências Ambientais e Saúde. E-mail: eng.ambiental.luana@gmail.com

${ }^{2}$ Orientador, Geólogo, doutor em Geociências e Meio Ambiente. Email: rubin@pucgoias.edu.br
} 
países em desenvolvimento, que ainda não possuem uma base sólida e bem estruturada no que diz respeito ao saneamento. Os mesmos autores ainda afirmam que os componentes de saneamento possuem uma forte interface entre si, impelindo o desenvolvimento urbano com base na gestão integrada, porém o que se percebe é que apenas os problemas são vistos de maneira integrada.

Dentre os recursos naturais necessários à vida, o mais importante, sem dúvida, é a água. Componente indispensável da maioria dos ecossistemas, ela pode ser diretamente relacionada com a alta diversidade de espécies encontradas em determinadas regiões. $\mathrm{O}$ controle da água pode fazer fortunas, sustentar o poder de políticos e definir o desenvolvimento que uma região, país ou sociedade pode alcançar, uma vez que a água é indispensável na realização de quase todas as atividades humanas. Em nível global, o ciclo hidrológico é um dos mais importantes para a humanidade, sendo, ao mesmo tempo, um dos mais vulneráveis às perturbações antropogênicas (VALLE, COSTA, ROA, 2006). Segundo o autor (BARRELA, 2001, p.187),

O termo bacia hidrográfica refere-se a uma compartimentação geográfica natural delimitada por divisores de água formados nas regiões mais altas do relevo, onde as águas pluviais ou escoam superficialmente formando riachos e rios, ou infiltram no solo para formação de nascentes e lençol freático.

A construção e o desenvolvimento urbano alteram o meio natural pré-existente, modificando a paisagem e configurando o espaço natural com construções humanas, alterando a cobertura vegetal e provocando vários efeitos que modificam os componentes do ciclo hidrológico natural. Com a urbanização, a cobertura da bacia é alterada sendo substituída por pavimentos impermeáveis e são introduzidos condutos para escoamento pluvial.

A rapidez do processo de urbanização causa uma série de impactos, tanto de ordem ambiental, como de ordem social, como por exemplo, a destruição da fauna e da flora, a poluição da água e do solo, seja pelo assoreamento e por retenção danosa dos corpos de água, ou por acúmulo de sólidos e de outros componentes. Destaca-se também os transtornos sociais fruto do crescimento da pobreza e da marginalidade urbana.

Uma alternativa errônea de algumas gestões é pensar que proteger pontualmente as áreas de nascentes irá garantir a manutenção do equilíbrio hidrológico, já que elas são o 
resultado de uma dinâmica complexa da água que envolve desde a recarga até a descarga, promovida por processos superficiais e subsuperficiais. Entretanto as alterações nos volumes de água subterrânea e nas modificações nas áreas de contribuição à montante são potencialmente impactantes às nascentes. Nesse sentido, a bacia hidrográfica ganha importância como unidade de gestão e proteção de nascentes (FELIPPE; MAGALHÃES JR., 2012).

Na urbanização de Araguaína, é notória a explosão demográfica com os rápidos e volumosos movimentos migratórios que determinaram crescimento populacional de 10.826 para 150.52 habitantes entre 1960 a 2010, e intensas transformações na cidade, com a proliferação de bairros, setores urbanos e vilas residenciais (SILVA, 2012).

O presente estudo tem como objetivo geral apresentar um diagnóstico ambiental da bacia do Córrego Baixa Funda em Araguaína - TO, afluente do rio Lontra, o qual desagua no rio Araguaia (Figura 1). O estudo desses impactos é importante para a urbanização adequada de uma cidade, pois quando não planejada, as consequências podem ser de ordem social, econômica e de saúde pública. Os resultados aqui apresentados são parciais, uma vez que a pesquisa se encontra em desenvolvimento.

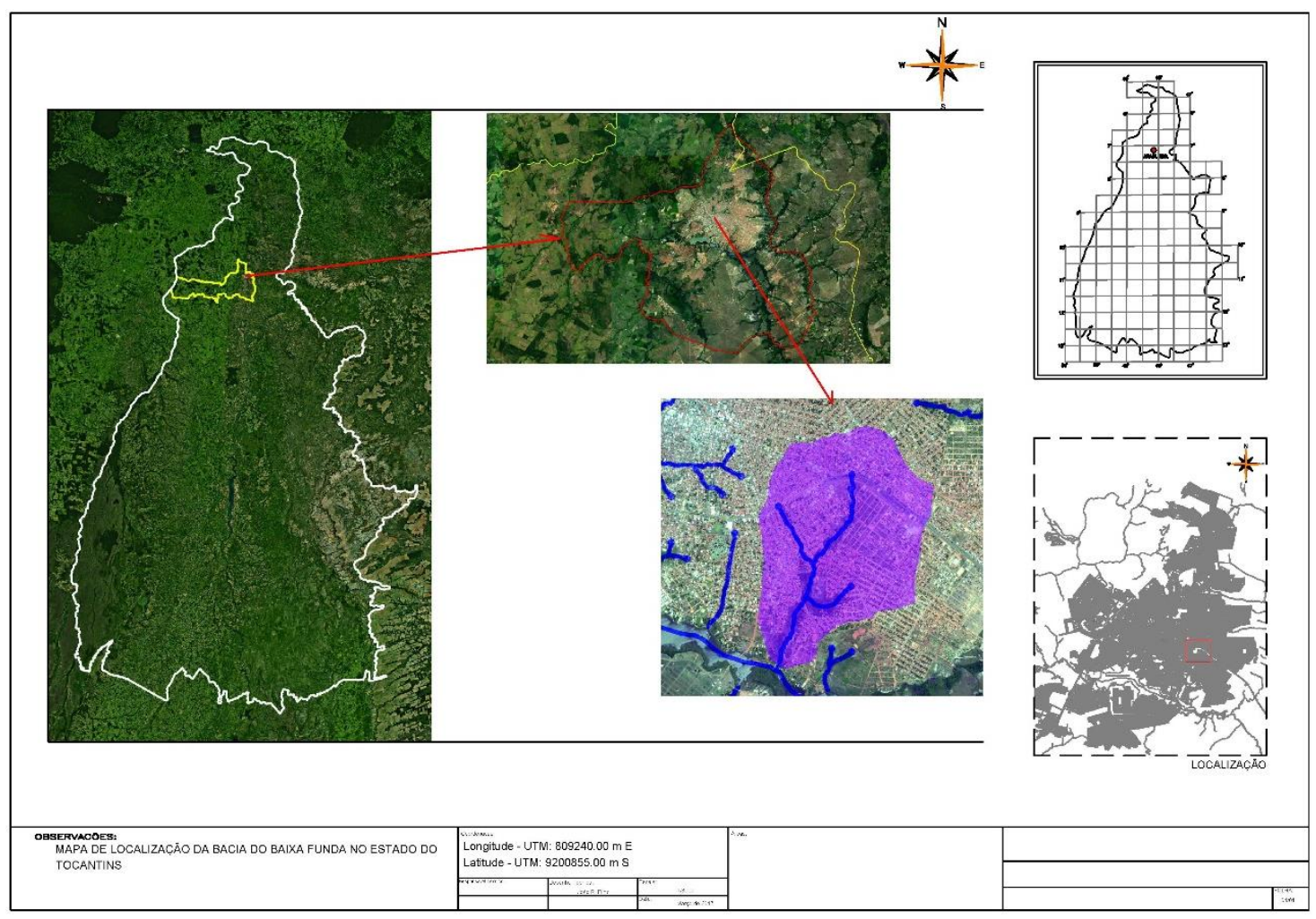

Figura 1 - Localização da área de estudo. Fonte: Seplan/Araguaína (2016). 


\section{METODOLOGIA}

O estudo é observacional com abordagem quantitativa e qualitativa, e composto por três etapas: gabinete, campo e laboratório.

\section{- Gabinete}

No gabinete foi realizada pesquisa bibliográfica referente ao tema, caraterização da área de pesquisa, escolha dos pontos amostrais para coleta de água, estratégia de percorrimento da área, análise e interpretação dos dados de campo e de laboratório.

A área da bacia hidrográfica em estudo, com 5,4Km² (Figura 2), abrange 20 bairros do município de Araguaína: St. Palmas, Santa Terezinha, Coimbra, Céu Azul, Tiúba, Itaipu, Santa Luzia, Residencial Camargo, Eldorado, São João, St. Tocantins, Vila Ribeiro, Loteamento Barros, St. Carajás, Vila Nova, Parque Primavera, Vila Bragantina, St. Raizal, Araguaína Sul e Jardim das Flores. A bacia está quase totalmente urbanizada, com residências e comércios, destacando-se lavajatos, oficinas, serralherias e hipermercados.

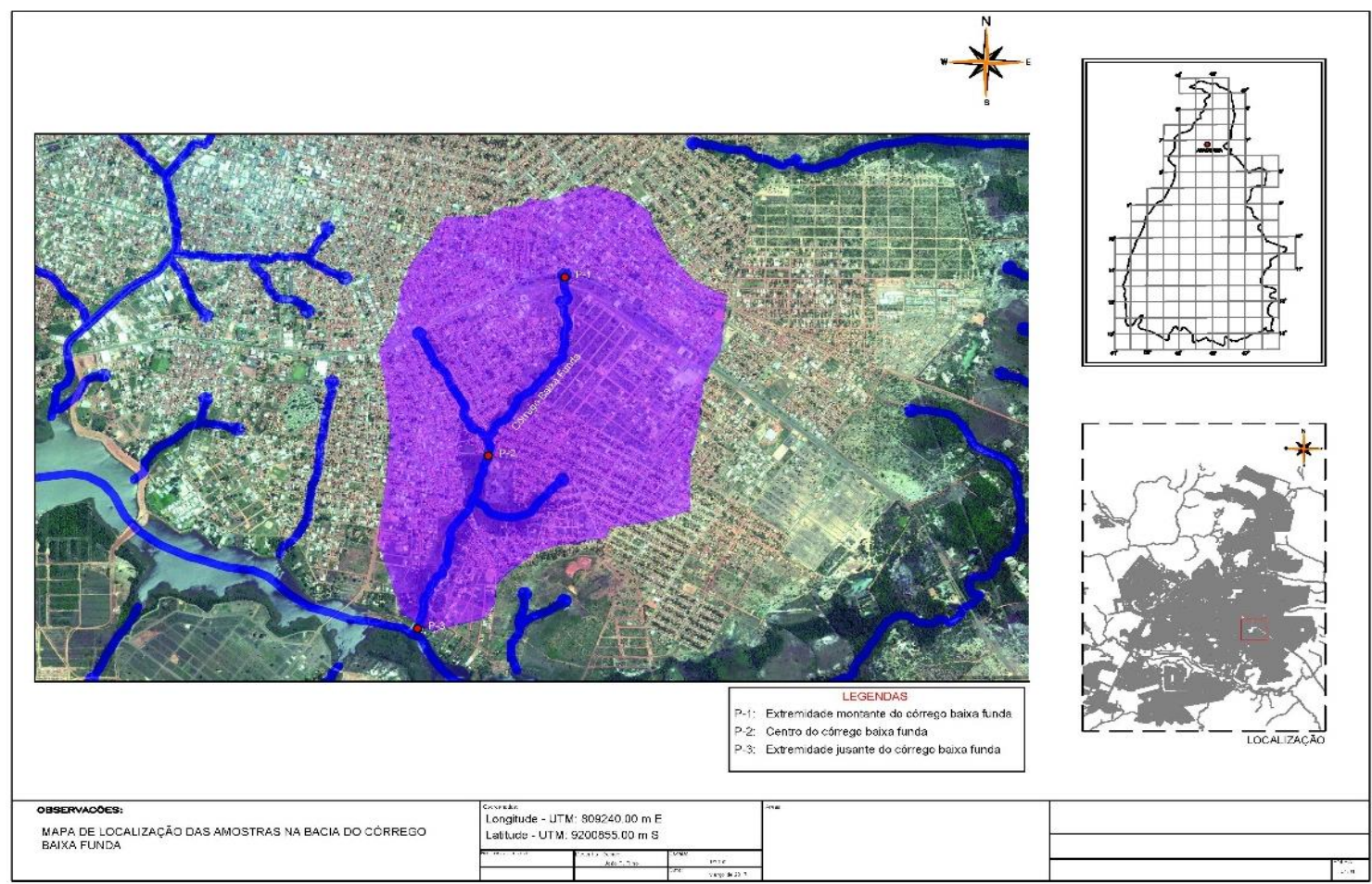

Figura 2: Imagem de satélite com a delimitação da área de estudo e pontos de coleta de água. Fonte: Seplan/Araguaína (2016).

\section{- Campo}

Percorrimento da área para identificação e descrição de pontos indicadores de impactos ambientais utilizando-se mapas e cartas temáticas como geologia, solos, geomorfologia e 
topográfico, além de imagens de satélite. Também foi realizado registro fotográfico e obtenção de coordenadas utilizando-se GPS modelo Garmim Montana 650. Foram identificados 10 pontos para a abordagem do tema da pesquisa, que estão sendo estudados.

A caracterização dos pontos levou em conta o potencial de impacto para a população, como em relação ao deslocamento, no caso de processos erosivos; de impacto a saúde, no caso de depósitos tecnogênicos construídos (descarte de lixo irregular); de impacto na qualidade da água, como lançamento de esgotos sem tratamento, por exemplo.

\section{-Laboratório}

A coleta das amostras de água foi planejado para os meses de março (já realizada) e setembro de 2017, compreendendo o período chuvoso e de estiagem. Serão realizadas coletas em três pontos: extremidade montante, no centro e extremidade jusante do córrego (Figura 2).

Os métodos e normas dos trabalhos de coleta das amostras e análises laboratoriais estão fundamentadas pelo Standard Methods for the Examination of Water and Wastewater (AWWA, 2005).

Os parâmetros analisados são físicos, químicos e bacteriológicos de qualidade de água, que serão submetidos ao Índice de Qualidade das Águas (IQA) da CETESB. Todos as amostras coletadas são armazenadas em caixa térmica e mantidas refrigeradas até o início do processo analítico no laboratório.

Os parâmetros físicos que serão analisados são: cor, turbidez, temperatura da água e do ar e resíduo total; parâmetros químicos: Demanda Bioquímica do Oxigênio, Demanda Química do Oxigênio, fósforo total, Oxigênio Dissolvido, $\mathrm{pH}$ e nitrogênio total; parâmetros bacteriológicos: coliformes totais e termotolerantes.

As análises serão realizadas no Laboratório de Controle e Monitoramento Ambiental da Pontifícia Universidade Católica - Goiás, em Goiânia.

\section{RESULTADOS E DISCUSSÃO}

A primeira campanha de coleta das amostras foi realizada em março, no período chuvoso, e os resultados indicam que a qualidade da água está de regular a insatisfatória de acordo com a resolução CONAMA 357/2005 (Tabela 1). 
Tabela 1: Resultado das análises no período chuvoso.

RESULTADOS ANALITTCOS:

\begin{tabular}{|c|c|c|c|c|c|c|c|}
\hline \multirow{2}{*}{ PARÂMETRO } & \multicolumn{7}{|c|}{ RESULTADOS: } \\
\hline & $\begin{array}{c}\text { BAIXA } \\
\text { FUNDA } \\
01 \\
\text { Coordenada } \\
\text { geográfica: } \\
7^{\circ} 11^{\prime} 52^{\prime \prime} \\
48^{\circ} 11 ' 27^{\prime} \\
258 \mathrm{~m} \\
\end{array}$ & 01 - IQA & $\begin{array}{c}\text { BAIXA } \\
\text { FUNDA } \\
02 \\
\text { Coordenada } \\
\text { geográfica: } \\
7^{\circ} 12^{\prime} 46^{\prime} \text { ' } \\
48^{\circ} 11^{\prime} 47^{\prime}, \\
242 \mathrm{~m}\end{array}$ & 02 - IQA & $\begin{array}{c}\text { BAIXA } \\
\text { FUNDA } \\
03 \\
\text { Coordenada } \\
\text { geográfica: } \\
7^{\circ} 13^{\prime} 15^{\prime} " \\
48^{\circ} 12^{\prime} 0,26^{\prime \prime} \\
227 \mathrm{~m} \\
\end{array}$ & 03 - IQA & UNIDADE \\
\hline Horário da coleta & 14.29 & - & $15: 15$ & - & $15: 40$ & - & $\mathrm{h} / \mathrm{min}$ \\
\hline Temperatura do ar & 28 & - & 28 & - & 28 & - & ${ }^{\circ} \mathrm{C}$ \\
\hline Temperatura da água & 27 & 9 & 27,8 & 9 & 26,8 & 9 & ${ }^{\circ} \mathrm{C}$ \\
\hline $\mathrm{pH}$ & 6,93 & 1 & 7,29 & 1 & 7,4 & 1 & - \\
\hline Turbidez & 12,88 & 0,63 & 31,2 & 1,54 & 36,1 & 1,78 & NTU \\
\hline Fósforo Total & $<0,01$ & 0 & $<0,01$ & 0 & $<0,01$ & 0 & $\mathrm{mg} \mathrm{P} / \mathrm{L}$ \\
\hline Nitrogênio Total & $<0,01$ & 0 & $<0,01$ & 0 & $<0,01$ & 0 & $\mathrm{mg}-\mathrm{N} / \mathrm{L}$ \\
\hline Resíduo Total & 337 & 21,42 & 260 & 16,6 & 258 & 16,47 & $\mathrm{mg} / \mathrm{L}$ \\
\hline OD & 31,23 & 10,41 & 33,2 & 11,06 & 15,84 & 5,28 & $\mathrm{mg} \mathrm{O}_{2} / \mathrm{L}$ \\
\hline DBO & 23,78 & 1,53 & 24,72 & 1,59 & 7,76 & 0,5 & $\mathrm{mg} \mathrm{O}_{2} / \mathrm{L}$ \\
\hline DQO & $<50$ & - & $<50$ & - & $<50$ & - & $\mathrm{mg} \mathrm{O}_{2} / \mathrm{L}$ \\
\hline Coliformes Totais & $5 \times 10^{3}$ & - & $1,6 \times 10^{4}$ & - & $9 \times 10^{3}$ & - & $\mathrm{NMP} / 100 \mathrm{~mL}$ \\
\hline Coliformes Termotolerantes & $5 \times 10^{2}$ & 3 & $3 \times 10^{3}$ & 3 & $9 \times 10^{3}$ & 3 & $\mathrm{NMP} / 100 \mathrm{~mL}$ \\
\hline $\begin{array}{l}\text { ONTO } \\
\text { ONTO }\end{array}$ & חתיוני & LA & & & & & \\
\hline
\end{tabular}

A tabela demonstra os parâmetros de análise de água segundo a CONAMA 357/2005. Os parâmetros físicos, químicos e bacteriológicos obtidos indicam que Índice de qualidade da água, encontram-se insatisfatórios segundo os parâmetros adotados pela CETESB.

Se observarmos a Demanda Bioquímica de Oxigênio - DBO, representa a quantidade de oxigênio necessária para oxidar a matéria orgânica presente na água através da decomposição microbiana aeróbia. A DBO 5,20 é a quantidade de oxigênio consumido durante 5 dias em uma temperatura de $20^{\circ} \mathrm{C}$ (CETESB, 2011). Os dados obtidos na Tabela 1 indicam que esse parâmetro está insatisfatório.

Os organismos aquáticos necessitam de oxigênio dissolvido para respirar. Com a poluição das águas, proveniente de efluentes sanitários dispostos irregularmente nos recursos hídricos apresentam baixa concentração de oxigênio dissolvido pois o mesmo é consumido no processo de decomposição da matéria orgânica. Na tabela 1 , se observa que esse parâmetro também está insatisfatório indicando que a vida aquática está comprometida.

O Ponto-1 localizado na extremidade montante do Córrego Baixa Funda, próximo a nascente, recebe um significativo volume de água do escoamento superficial, a partir ruas pavimentadas, em uma área onde existem diversas atividades comerciais potencialmente 
poluidoras do córrego Baixa Funda, como Postos de Gasolina e oficinas mecânicas. Nas margens do córrego também existem processos erosivos, alguns recebendo lixo doméstico, tornando-se um depósito tecnogênico construído.

O P-2 localizado na porção média do Córrego Baixa Funda, próximo a confluência com o Córrego Cará, também apresenta processos erosivos contendo resíduos doméstico, comerciais e restos da construção civil no interior, além de lançamento de efluentes domésticos e comerciais sem tratamento.

O Ponto 3 apresenta condições semelhantes aos Pontos 1 e 2 .

Os demais 10 pontos caracterizados no interior da bacia, e fora do canal do córrego Baixa Funda, indicam uma ocupação desordenada, com a retirada da mata ciliar, processos erosivos nas encostas, presença de depósitos tecnogênicos, deficiente sistema de captação das águas pluviais, entro outros. Esta realidade favorece o assoreamento do canal com resíduos de natureza diversa, além de erosões junto as margens.

\section{CONCLUSÕES PARCIAIS}

O estudo em desenvolvimento já permite a identificação de um quadro preocupante em relação as condições ambientais do córrego Baixa Funda, principalmente em relação a ocupação urbana desordenada, com um agravamento das questões sócio ambientais. Por estar localizado em área urbana, merece maior atenção por parte das autoridades no que tange à realização de obras que possibilitem a minimização dos impactos negativos. Para tanto o diagnóstico ambiental da área é um instrumento importante para a proposição de medidas mitigatórias e subsidiar novas pesquisa na área e em outras bacias hidrográficas do munícipio de Araguaína.

\section{REFERÊNCIAS}

AWWA. Standard Methods for the Examination of Water and Wastewater. Port City Press. Baltimore, Maryland. 2005.

BARRELA, W. et al. As relações entre as matas ciliares os rios e os peixes. In: RODRIGUES, R.R.; LEITÃO FILHO; H.F. (Ed) Matas ciliares: conservação e recuperação. 2.ed.São Paulo: Editora da Universidade de São Paulo, 2001.

BRASIL. Resolução CONAMA n 357/2005. Ministério do Meio Ambiente, Governo do Brasil. Diário Oficial da União 17 de julho de 2005. 2005. 
BRASIL. 2006. Diretriz Nacional do Plano de Amostragem da Vigilância em Saúde Ambiental relacionada à qualidade da água para consumo humano. Ministério da Saúde, Governo do Brasil. Brasília.

CETESB. Companhia Ambiental do Estado de São Paulo. 2011. Guia Nacional de Coleta e Preservação de Amostras. ANA. Brasília, DF. 327 p.

FELIPPE, M. F.; MAGALHÃES JR., A. P. M. Impactos ambientais macroscópicos e qualidade das águas em nascentes de parques municipais em Belo Horizonte, MG. Geografias, v. 8, n. 2, p. 8-23, 2012.

INSTITUTO BRASILEIRO DE GEOGRAFIA E ESTATÍSTICA (IBGE). Perfil dos municípios brasileiros. Brasília, 2014.

NEVES, M. G. F. P. das e TUCCI, C. E. M. Resíduos Sólidos na Drenagem Urbana: Aspectos Conceituais. Revista Brasileira de Recursos Hídricos, v. 13, n. 3, jul/set 2008a, p. 125-135.

VALLE, L. E. R.; COSTA, R. B.C.; ROA, R. A. R.; Percepção dos produtores rurais sobre práticas conservacionistas na Bacia do Córrego Guariroba, Campo Grande - MS, Multitemas, Campo Grande-MS, n. 34, p. 105-119, nov. 2006. 